\title{
Las problemáticas de género: una introducción para su aplicación en estudios de contabilidad ${ }^{1}$
}

\author{
Martha Giovanna Acosta Sahamuel ${ }^{2}$ \\ Ruth Alejandra Patiño Jacinto ${ }^{3}$ \\ Gloria Milena Valero Zapata ${ }^{4}$ \\ Michael Andrés Díaz Jiménez ${ }^{5}$
}

Recibido: 20 de septiembre 2015

Aprobado: 15 de noviembre de 2015

\begin{abstract}
1 Artículo de revisión realizado dentro del proyecto de investigación: Contabilidad y Mujer, financiado por la Facultad de Contaduría Pública de la Universidad Santo Tomás en el año 2014.

2 Contadora pública, Universidad Nacional de Colombia. Magíster en Educación, Universidad Santo Tomás. Miembro del grupo de investigación contaduría: Información, control e impacto social. Correo: marthagiovanna@gmail.com

3 Contadora pública, Universidad Nacional de Colombia. Magíster en Ciencias Económicas, Universidad Santo Tomás. Coordinadora del Centro de Investigación de la Facultad de Contaduría Pública de la Universidad Santo Tomás CICOP. Líder del grupo de investigación contaduría: Información, control e impacto social. Correo: alejandrapatino@usantotomas.edu.co

4 Contadora pública, Universidad Nacional de Colombia, con estudios en maestría en Medio Ambiente y Desarrollo de la misma universidad, docente e investigadora de la Facultad de Contaduría Pública de la Universidad Santo Tomás. Miembro del grupo de investigación contaduría: Información, control e impacto social. Correo: gloriavalero@usantotomas.edu.co

5 Contador público, Universidad Nacional de Colombia. Miembro del grupo de investigación contaduría: Información, control e impacto social. Correo: michaeldiazj@usantotomas.edu.co
\end{abstract}


Acosta, M., Patiño R., Valero, G. \& Díaz, M. (2015). Las problemáticas de género: una introducción para su aplicación en estudios de contabilidad. Activos, 25, 33-72.

\section{Clasificación JEL: Z19.}

\section{Resumen}

El presente trabajo constituye la revisión de publicaciones en distintos contextos relacionados con problemáticas y tendencias ideológicas relacionadas con las mujeres; se propone una caracterización en Europa, Estados Unidos, Canadá, Latinoamérica, Asia y África, con el propósito de identificar unas condiciones de la situación a nivel general y autores representativos en el tema de referencia, con el propósito de utilizar posteriormente los resultados, en otros escritos, vinculándolos con las investigadoras contables. La metodología utilizada fue cualitativa-documental, por cuanto se basó en la revisión de publicaciones con problemáticas relacionadas con las mujeres. El resultado más significativo es que en todos los contextos se presentan problemáticas, algunos con mayor impacto que otros, sin embargo, asimismo surgen autores muchas veces como respuesta a la necesidad de proponer soluciones o simplemente dar a conocer los problemas, muchos de los cuales han tenido gran transcendencia social a lo largo de la historia.

\section{Palabras clave}

Mujer, problemáticas de las mujeres, mujeres en distintos contextos.

Acosta, M., Patiño R., Valero, G. \& Díaz, M. (2015). Gender issues: introduction for application in accounting studies. Activos, $25,33-72$.

\section{Summary}

This work is a review of publications of different contexts, ideological tendencies and issues related to women; a characterization is proposed in 
Europe, U.S, Canada, Latin America, Asia and Africa, with the aim of identifying some general conditions of the situation and representative authors on the subject, in order to use these results in other writings, linking them together with accounting research. We used a qualitative-documentary methodology, based on the revision of publications on women issues. The most significant result is that in all contexts there are issues, some of greater impact than others, however; some authors emerge in response to the need of proposing solutions or simply to make a public clarification of problems, many of which have had great social significance throughout history.

\section{Keywords}

Women, women's issues, women in different contexts.

Acosta, M., Patiño R., Valero, G. \& Díaz, M. (2015). Les problématiques du genre: une introduction pour son application dans les études comptables. Activos, 25, 33-72.

\section{Résumé}

Ce projet est une révision des publications dans des différents contextes liés avec les problématiques et les tendances idéologiques liées aux femmes ; une caractérisation proposée en Europe, Etats Unis, Canada, Amérique Latine, Asie et Afrique, dans le but d'identifier les conditions de la situation au niveau générale et les auteurs représentatifs sur le sujet de référence, afin d'utiliser les résultats dans d'autres écrits et les relier avec les chercheurs comptables. La méthodologie utilisée est de type qualitative-documentaire, parce que elle était fondée dans la révision des publications avec des problématiques liées aux femmes. Le résultat plus significatif est que dans toutes les contextes il y a des problématiques, certains avec plus d'impact que d'autres. Cependant, des auteurs émergent souvent comme une réponse à la nécessité de proposer des solutions ou simplement pour faire connaitre 
les problèmes, dont beaucoup ont eu une grande signification sociale à travers de l'histoire.

\section{Mots clés:}

Femme, problématiques des femmes, femmes dans différents contextes.

\section{Introducción}

La mujer como categoría de estudio se ha abordado en múltiples trabajos y a partir de diferentes perspectivas disciplinares y metodológicas que van desde análisis históricos psicológicos, sociológicos, antropológicos, políticos, entre otros tantos; pero que en palabras de Collazo (2005) "se ha visto eclipsada por las nociones de sexo, rol o culturales” (p. 52), estableciendo patrones de comportamiento en cada sociedad. Sin embargo, es de resaltar la importancia que esta categoría ha tomado en estudios relacionados con movimientos feministas, problemáticas sociales de gran impacto en las que la desigualdad es un factor determinante.

Los problemas de tipo social, económico y político en cuanto al papel de la mujer en distintas sociedades ha sido evidente, de tal forma que es un tema transversal a distintos lugares y épocas, de tal forma que existe la necesidad de contrastar las diferentes visiones respecto a las problemáticas vigentes e inclusive conocerlas, las cuales en algunas áreas geográficas son inclusive desconocidas o ignoradas.

El presente trabajo busca dar una mirada general a las problemáticas de las mujeres en distintas ubicaciones geográficas, a partir de las visiones que diversos autores tienen sobre el particular, dado lo anterior se desarrolla a partir de la revisión bibliográfica, que en palabras de Ramos (2003), tiene como propósito "examinar la bibliografía publicada y situarla en cierta perspectiva” (p. 83), lo cual conduce a revisar fuentes primarias de 
información, generar unas ideas y concluir acerca de un tema en particular. Con base en esto, se realiza la revisión documental, con el fin de establecer las características y desarrollos de los movimientos feministas desde los años 70; de esta manera se establecen unos criterios o términos de búsqueda que para el caso son: gender studies, feminism movements, theories feminists, contemporary feminism, feminism, genre, woman, género, mujer, estudios feministas, estudios de género.

La búsqueda se realizó identificando autores por países, puesto que la idea fundamental es tratar de establecer las tendencias por contexto geográfico, y se procede a revisar el resumen de los artículos con el fin de establecer los documentos que brinden aportes sobre las principales tendencias feministas. Las bases de datos revisadas fueron: Ebsco Host Academic Search Complete y JSTOR, en cuanto a los que vinculan el tema contable está el Accounting, Organization and Society.

Por lo anterior, el documento se desarrolla como un acercamiento histórico a las principales tendencias, movimientos y problemáticas relacionadas con la mujer a través de la revisión documental de los hechos más relevantes desde los años 70 a la actualidad en los contextos de Canadá, Estados Unidos, Latinoamérica, África, Asia y Europa como principal antecedente de los demás contextos.

\section{Resultados}

\section{Europa}

El continente Europeo es el principal referente de los movimientos y teorías feministas que han prevalecido durante varias décadas, con un mayor desarrollo a partir de la segunda mitad del siglo XX, en relación a los diferentes aportes en torno a minimizar la desigualdad de género y a promover la inclusión de las mujeres en los diferentes espacios mediante mecanismos legales y de participación social con entidades estatales y privadas (Ramírez, 2003). 
Francia es el país europeo con los grupos de investigación más representativos frente al tema estudiado, entre los que se resaltan: Artemisia, Centre Louise Labé, Centre de recherches et d'information féministes [CRIF], Egalité des chances entre les femmes et les hommes [DIU], Equipe SimoneSagesse, Savoirs, genre et rapports sociaux de sexe, Genre et Rapports Sociaux [GERS], Institut de Reserche sur les Sociétés Contemporaines [IRESCO] y algunas revistas como Bulletin del ANEF, Cahiers du CEDREF, Clio, Histoire, Femmes et Sociétés, entre otros (Ramírez, 2003).

Como producto de lo anterior, en la década de los setenta se incrementaron y expandieron los movimientos feministas, logrando transformaciones importantes en las condiciones de desigualdad existentes; dichos cambios fueron el resultado de leyes e instituciones defensoras de los derechos de las mujeres y contribuyeron a garantizar la igualdad de género en diferentes aspectos. Entre las diferentes actividades se destacan las labores destinadas a luchar en contra de la dominación masculina desde la familia, con el fin de atacar el problema desde la raíz y así lograr una paridad en espacios que van desde lo social, pasando por lo económico, lo político y lo educativo, entre otros. Con esta premisa se ataca el patriarcado como sistema tradicional (Fiscer, 2013).

Los lineamientos y reformas que se han configurado en la legislación europea, se contemplan en temas específicos como el aborto, el matrimonio y la violencia sexual; provocando un paso importante hacia el movimiento de liberación de la mujer, en ciertos casos sobrepasando los límites tradicionales; propiciando movimientos de feminismo radical (Ávila, 2012). Algunas de las instituciones europeas pioneras en la defensa de los derechos de la mujer se presentan a continuación en la tabla 1 : 
Tabla 1. Instituciones europeas pioneras en la defensa de los derechos de la mujer.

\begin{tabular}{|c|c|}
\hline Institución & Descripción \\
\hline $\begin{array}{l}\text { Convención Europea de } \\
\text { Derechos Humanos. }\end{array}$ & $\begin{array}{l}\text { Entra en funcionamiento a partir de 1953, y tiene } \\
\text { como objetivo velar por la defensa de los derechos } \\
\text { humanos fundamentales y los de toda la población eu- } \\
\text { ropea, incluyendo la igualdad de oportunidades para } \\
\text { hombres y mujeres en sus diferentes aspectos. }\end{array}$ \\
\hline $\begin{array}{l}\text { Action Catholique Générale } \\
\text { Fémile [ACGF]. }\end{array}$ & $\begin{array}{l}\text { Se dedica al trabajo por la igualdad de género y la dig- } \\
\text { nidad de las mujeres en la sociedad. Se crea en } 1955 \\
\text { luego de una fusión con dos asociaciones francesas en } \\
\text { un entorno en el que prevalecían las prácticas antirre- } \\
\text { ligiosas y las leyes laicas. }\end{array}$ \\
\hline $\begin{array}{l}\text { Movimiento Democrático de } \\
\text { Mujeres [MDM]. }\end{array}$ & $\begin{array}{l}\text { Se creó en España en 1965, y en ella participaban } \\
\text { amas de casa, trabajadoras, estudiantes, mujeres } \\
\text { de diferente estatus y condición social, distintas } \\
\text { religiones, creencias, costumbres, etc. Se trataban } \\
\text { temas abiertos sobre situaciones generales y posturas } \\
\text { de la mujer en la sociedad. Fue considerado como el } \\
\text { movimiento más importante en España. }\end{array}$ \\
\hline $\begin{array}{l}\text { Association BPW France } \\
\text { - Union Professionnelle } \\
\text { Féminine [UPF]. }\end{array}$ & $\begin{array}{l}\text { Promueven el ámbito laboral de las mujeres, moti- } \\
\text { vándolas a actualizarse y a defender cualquier tipo de } \\
\text { discriminación económica, civil y política, además de } \\
\text { suscitar la mejora de las carreras profesionales para } \\
\text { las mujeres. }\end{array}$ \\
\hline $\begin{array}{l}\text { Association Française } \\
\text { Femmes \& Sciences. }\end{array}$ & $\begin{array}{l}\text { Dentro de sus objetivos principales se encuentra } \\
\text { incrementar la presencia de las mujeres en carreras } \\
\text { científicas y técnicas, incentivándolas a la participa- } \\
\text { ción activa en estos campos, mejorando las perspecti- } \\
\text { vas y aumentando los espacios para las mujeres en los } \\
\text { diferentes ámbitos de actuación. }\end{array}$ \\
\hline Moviment de Dones. & $\begin{array}{l}\text { Fue fundado en Barcelona en 1975, con una participa- } \\
\text { ción mucho más marcada de la política de izquierda } \\
\text { y feministas españolas de gran bagaje, como Lidia } \\
\text { Falcón y Cristina Alberdi. }\end{array}$ \\
\hline Du côte des femmes. & $\begin{array}{l}\text { Sus objetivos fundamentales en pro de la defensa de } \\
\text { los derechos de las mujeres, es contar con asistencia } \\
\text { jurídica para temas específicos de protección para las } \\
\text { mujeres en acceso a la educación, temas laborales, } \\
\text { matrimonios forzados y casos de violencia. }\end{array}$ \\
\hline
\end{tabular}




\begin{tabular}{|c|c|}
\hline Institución & Descripción \\
\hline Les Pénélopes. & $\begin{array}{l}\text { Promueve la participación activa de las mujeres en } \\
\text { el diseño, creación y participación de las nuevas } \\
\text { tecnologías como una red internacional multicultural, } \\
\text { en las que la interacción con aportes innovadores en } \\
\text { aspectos tecnológicos son su objetivo principal a favor } \\
\text { de todas las mujeres del mundo. }\end{array}$ \\
\hline $\begin{array}{l}\text { Frente de Liberación de la } \\
\text { Mujer. }\end{array}$ & $\begin{array}{l}\text { Se crea en } 1975 \text { en Madrid, como una propuesta de } \\
\text { organización femenina para poner frente a las proble- } \\
\text { máticas políticas de la época, aunque es criticado por } \\
\text { las feministas radicales. }\end{array}$ \\
\hline $\begin{array}{l}\text { Mnémosyne. Association } \\
\text { pour le Développement de } \\
\text { I'Histoire des Femmes et du } \\
\text { Genre. }\end{array}$ & $\begin{array}{l}\text { Conserva investigaciones desarrolladas a los largo de } \\
\text { la historia en temas de género e historia de las mujeres } \\
\text { en los diferentes campos (universitarios, instituciona- } \\
\text { les, culturales, investigativos, etc.). }\end{array}$ \\
\hline Prochoix. & $\begin{array}{l}\text { Se encarga de la investigación "en pro de la defensa de } \\
\text { las libertades individuales amenazadas y fragilizadas } \\
\text { por esencialismos, racismos, integrismos e ideología } \\
\text { totalitaria o antielección” (Ramirez, 2003, p. 175). }\end{array}$ \\
\hline $\begin{array}{l}\text { Société Internationale pour } \\
\text { I'Étude des Femmes de } \\
\text { I'Ancien Régime [SIEFA]. }\end{array}$ & $\begin{array}{l}\text { Su objetivo principal es reunir, difundir y promover } \\
\text { los resultados de los estudios y las investigaciones rea- } \\
\text { lizadas en torno a las mujeres, además de profundizar } \\
\text { en la reflexión y el conocimiento en relación al género } \\
\text { y su construcción. }\end{array}$ \\
\hline $\begin{array}{l}\text { Lucha Antiautoritaria de } \\
\text { Mujeres Antipatriarcales y } \\
\text { Revolucionarias [LAMAR]. }\end{array}$ & $\begin{array}{l}\text { Se crea en } 1976 \text { como un movimiento radical en el que } \\
\text { se trabajaría por la lucha en contra del machismo y } \\
\text { del patriarcado que predominaba en ese entonces. Sus } \\
\text { labores fueron apoyadas por el Colectivo Feminista } \\
\text { Pelvis, quienes trabajaban el tema del moralismo y } \\
\text { las corrientes católicas españolas. Más tarde y tras } \\
\text { movilizaciones y múltiples campañas logran en } 1985 \\
\text { una leve modificación al código penal en lo relativo } \\
\text { al aborto. }\end{array}$ \\
\hline $\begin{array}{l}\text { Union Féminine Civique et } \\
\text { Sociale [UFCS]. }\end{array}$ & $\begin{array}{l}\text { Se preocupa por incentivar la participación de las } \\
\text { mujeres en cuanto a la actuación y comunicación de } \\
\text { valores democráticos: "pluralismo, tolerancia, auto- } \\
\text { nomía de decisión, civismo y solidaridad", además de } \\
\text { generar transformaciones en la sociedad en aspectos } \\
\text { como un tipo de sociedad más humana y respetuosa } \\
\text { en la igualdad de oportunidades. }\end{array}$ \\
\hline
\end{tabular}




\begin{tabular}{l|l}
\hline Institución & Descripción \\
\hline $\begin{array}{l}\text { Asociación para los derechos } \\
\text { de la mujer y el desarrollo } \\
\text { [AWID]. }\end{array}$ & $\begin{array}{l}\text { Su objetivo es fortalecer la participación femenina en } \\
\text { todos los espacios sociales y mejorar continuamente } \\
\text { lo derechos de las mujeres siempre en busca de una } \\
\text { igualdad, y eliminando todas las prácticas discrimina- } \\
\text { torias que se puedan presentar. }\end{array}$ \\
\hline $\begin{array}{l}\text { Association des Femmes } \\
\text { journalister [AFJ]. }\end{array}$ & $\begin{array}{l}\text { Fue creada en 1981, y desde entonces se encarga de } \\
\text { promover espacios equitativos y una buena imagen } \\
\text { para las mujeres en los medios de comunicación, } \\
\text { además difunde las noticias en torno a las actuaciones } \\
\text { más importantes de las mujeres. }\end{array}$ \\
\hline Coordinadora & $\begin{array}{l}\text { Se crea en 1985 como promotora de políticas a favor } \\
\text { de la igualdad femenina. }\end{array}$ \\
Feminista Estatal. &
\end{tabular}

Fuente: elaboración propia a partir de Ramirez, 2003; Fiscer, 2013.

En general las leyes y reglamentos que se consolidaron entre los años sesenta y ochenta modificaron el entorno social europeo, haciendo más incluyente a la mujer en espacios donde era discriminada; por lo cual se logró una igualdad de trato y se fortalece el acceso equitativo al mercado laboral. Entre los cambios legislativos más representativos se presentan a continuación:

Tabla 2. Principales cambios normativos en Europa a favor de la mujer, años 60 a 80.

\begin{tabular}{l|l}
\hline Leyes y Decretos & Aportes al tema de género \\
\hline $\begin{array}{l}\text { Decreto Ley del } 3 \text { de marzo } \\
\text { de } 1956\end{array}$ & $\begin{array}{l}\text { Restringe las casas de prostitución, y a partir de } 1962 \\
\text { bajo los fundamentos de esta Ley, se adhiere al con- } \\
\text { venio contra la trata de personas de la Organización } \\
\text { de Naciones Unidas [ONU]. }\end{array}$ \\
\hline $\begin{array}{l}\text { Legislación antidiscriminato- } \\
\text { ria de Gran Bretaña. La Sex } \\
\begin{array}{l}\text { Discrimination Act [SDA] y } \\
\text { la Equal Pay Act }\end{array}\end{array}$ & $\begin{array}{l}\text { Esta legislación se consolida a partir de 1975, con- } \\
\text { virtiéndose en las primeras leyes antidiscriminación } \\
\text { de Europa. }\end{array}$ \\
\hline $\begin{array}{l}\text { Equal Opportunity } \\
\text { Comission } \text { [EOC] }\end{array}$ & $\begin{array}{l}\text { Se estableció en 1976 con el fin de supervisar la } \\
\text { aplicación de la SDA. }\end{array}$ \\
\hline
\end{tabular}




\begin{tabular}{l|l}
\hline Leyes y Decretos & Aportes al tema de género \\
\hline $\begin{array}{l}\text { Reforma al estatuto de los } \\
\text { trabajadores 1981-1985 }\end{array}$ & $\begin{array}{l}\text { Desaparecen las discriminaciones directas al empleo } \\
\text { femenino y se hacen regulaciones sobre las jornadas } \\
\text { laborales de las mujeres. }\end{array}$ \\
\hline Ley del divorcio (España 1981) & $\begin{array}{l}\text { Fue uno de los aportes más importantes de la época } \\
\text { para reafirmar la liberación femenina. }\end{array}$ \\
\hline $\begin{array}{l}\text { Ley de la despenalización del } \\
\text { aborto 1985 }\end{array}$ & $\begin{array}{l}\text { Se despenaliza el aborto bajo tres supuestos fun- } \\
\text { damentales que aún prevalecen: riesgo grave de la } \\
\text { gestante, violación y malformaciones en el feto. }\end{array}$ \\
\hline Políticas públicas de Noruega & $\begin{array}{l}\text { A partir de 1986 se consolida una política que involu- } \\
\text { cra más a las mujeres en participaciones democráti- } \\
\text { cas reforzando "los estereotipos de género". }\end{array}$ \\
\hline
\end{tabular}

Fuente: elaboración propia a partir de Heim y Bodelón, 2009.

Con relación a las autoras más representativas en temas de género y feminismo en Europa, se encontró una serie de posturas sincronizadas que marcan una tendencia, que prevaleció en la segunda mitad del siglo XX. Por ello se sintetiza a continuación las principales obras y sus exponentes.\$

Simone de Beauvoir fue una de las promotoras de la igualdad de condiciones y oportunidades en la formación intelectual y profesional; resaltando que la inferioridad de la mujer no era una problemática reciente, sino que estaba predestinada por un asunto histórico-cultural de ya varios siglos (Grau, 2014). Con base en lo anterior expuso que la causa de la opresión y de la subordinación, se fundamentaba en la exclusión social y las tendencias machistas llevadas a cabo en tiempos remotos, y que a partir de entonces, se conocía a la mujer como el sexo débil o como un ser inferior, llevándola a la categoría de la alteridad (un sujeto sin autonomía). "No se nace mujer: se llega a serlo" (Ciriza, 2012).

Beauvior en su obra $E l$ segundo sexo marca una pauta sobre la labor de la mujer en la sociedad, propone una nueva organización social más incluyente para las mujeres y no acepta la inferioridad física como causal de sumisión en la sociedad (Carnero, 2005); esta obra se caracteriza por ser una pieza fundamental para el desarrollo del feminismo europeo (Ávila, 2012). 
Siguiendo estos planteamientos, Hélène Cixous contempla que debe haber un cambio lingüístico para que haya un cambio social; por ello invita a las mujeres a desarrollar hábitos de escritura con un lenguaje propiamente femenino que las destaque en la sociedad e incentive a no vivir reprimidas por los hombres. Sus trabajos se basaron en temas experimentales, que buscaban estimular la presencia de las mujeres en todos los ámbitos sociales e ir en contraposición al pensamiento occidental machista, que considera el género femenino como el más débil y negativo (Estevez, 2003).

Por otro lado, Virginia Woolf prevalece como un referente en los estudios de género y del modernismo literario del continente europeo; puntualmente porque resalta en su obra la desigualdad económica y social y la inferioridad femenina como la problemática histórica de la sociedad patriarcal. En su libro, Una habitación propia, incentiva a las mujeres a escribir sobre cualquier tema, porque consideraba que era un primer paso, (Woolf, 1929).

En su obra Tres Guineas, Woolf hace una crítica al patriarcado desde tres perspectivas: educativa, laboral y acceso a movimientos progresistas. En la primera, manifiesta que existen limitantes para el acceso a la educación para las mujeres; de no existir, deberían seguir unas líneas de estudio diferentes para evitar futuros conflictos de poder y superioridad. En la segunda, desarrolla el tema de inserción de las mujeres a la vida laboral, en igualdad de condiciones y oportunidades. En la tercera perspectiva resalta que las mujeres no deben caer en la retórica de adherirse a las prácticas sobre paridad y justicia promovidas por los hombres, ya que significaría una pérdida de la diferencia y de la poca identidad que se ha adquirido (Ortega, 2002).

Una nueva corriente nace a mediados de los años setenta, se trata del feminismo de la diferencia, que se caracteriza por defender los atributos propios de las mujeres, para llegar a la igualdad en condiciones de no sometimiento. Luce Irigaray en su obra Speculum plantea que las mujeres para lograr esta igualdad no deben seguir un modelo masculino, porque de esta manera no se obtendría una verdadera identidad y se caería en la retórica de la obediencia a los ideales machistas, en el que la mujer no tendría la suficiente autonomía. Con base en lo anterior, las mujeres no deben ser 
consideradas como el "otro" sexo que complementa al hombre, al contrario, deben tener una propia identidad y un espacio propio en igualdad de condiciones y oportunidades (Ortega, 2002).

Algunas otras autoras del contexto europeo complementan las apreciaciones del feminismo de la diferencia. En Italia, en su manifiesto Rivolta femminile (Lonzi, 1970) correlaciona una serie de expresiones feministas con la carencia de autonomía de las mujeres, resaltando que la mujer no debe ser el reflejo del hombre ni debe seguir un modelo masculino como un rol absoluto, debe tener su propia libertad de pensamiento y un espacio incluyente en la sociedad que incrementará su autoestima.

Las posturas, lineamientos y criterios adoptados por cada una de las autoras demuestran la preocupación latente de la época; la discriminación de la mujer y el constante arraigo del sistema patriarcal, fueron las principales causas para incentivar los movimientos feministas que modificarían de manera radical el entorno social europeo y posteriormente el mundial. Aún se sigue trabajando sobre el tema y continúa la lucha femenina para la erradicación de todas las prácticas de discriminación y sometimiento.

\section{Estados Unidos}

Los constructos sociales y políticos han sido determinantes en los desarrollos de los movimientos feministas en los diferentes contextos que se analizarán, porque gestaron cambios en los mecanismos y en los fines de las movilizaciones; entre los cuales cabe mencionar particularidades como:

Estados Unidos donde los movimientos feministas han terminado por formar redes consolidadas de grupos de interés independientes y de organizaciones de presión, en otros sitios -como en Suecia o Noruega-, las feministas han alcanzado posiciones de responsabilidad en partidos políticos y en instituciones estatales. Y en otros países, las feministas han desarrollado muy escasos contactos con instituciones políticas formales para concentrarse, en cambios, ya en organizaciones populares (como 
en el Reino Unido), ya en el desarrollo de proyectos culturales (Duby y Perrot, 1993, p. 561).

Los movimientos realmente feministas se gestan en Norteamérica, hacia finales de los años cincuenta, en el periodo de la posguerra y se conocen como la segunda ola; traen consigo un número importante de cambios para las mujeres occidentales así como divisiones ideológicas, políticas y tácticas (Mendes, 2011) identificándose principalmente dos tendencias en Estados Unidos: la liberal y la radical, las cuales cuentan con exponentes como Betty Friedman y Kate Millet respectivamente (Ortega, 2002).

Las liberales presentaban como principal problema de las mujeres "su exclusión de la esfera pública, y propugnaban reformas relacionadas con la inclusión de las mismas en el mercado laboral" (Ortega, 2002, p. 9). Mientras que las radicales se centran en el patriarcado como "la clave de la dominación tanto femenina como de raza o clase" (Ortega, 2002, p. 11), puntualmente lo que tiene que ver con la dominación psicológica en ámbitos que van de lo sexual, lo familiar y lo político (Ortega, 2002); esta tendencia ideológica dominó el movimiento estadounidense, en torno a dos temas: el aborto y la enmienda que proponía la igualdad de género (Mendes, 2011; Travis, 2008).

La segunda ola del feminismo se vio reforzada por las mujeres sindicalizadas laboralmente, orientando sus preocupaciones al aumento salarial, el respeto de los otros trabajadores, las nociones tradicionales de género, la división sexual del trabajo y la discriminación asociada; las dinámicas de lucha frente a esos temas se ven formalizadas con la fundación de la National Organizatión for Woman (NOW) como una organización que pretendía promover y garantizar los derechos civiles de las mujeres, a través de construir coaliciones raciales; no obstante como se centraron en determinados trabajos, las mujeres que deseaban desarrollarse en trabajos no tradicionales fueron las primeras en generar división (Maclean, 1999). En palabras de Gordon (2013), la NOW es vista como la corriente que precedió el movimiento feminista socialista. 
Con el fin de resaltar otras tendencias que se gestaron durante la segunda ola, en el marco de la Nueva Izquierda ${ }^{6}$, de las luchas por los derechos civiles y los movimientos estudiantiles, se debe mencionar la corriente socialista, la cual históricamente es simbolizada por la protesta en el concurso de belleza Miss Estados Unidos en 1969 y se caracterizó por identificar que el capitalismo es el objeto de la dominación masculina, pero que es necesario construir nuevas teorías que rompan con las estructuras de género, raza y clase porque perpetúan la desigualdad y la explotación; se centraron en un compromiso con la democracia participativa y una oposición declarada con el leninismo y el maoísmo (Gordon, 2013).

La segunda ola del activismo femenino tuvo su mayor auge en los años setenta y perdió fuerza hacia finales, cuando las dinámicas se enfocaron en temáticas como la paz y feminismos ambientales (Mendes, 2011). De forma general se podría decir que transformó significativamente sinnúmero de aspectos, principalmente por las distintas políticas públicas que lograron gestar; entre los principales ámbitos que se vieron impactados se pueden mencionar: la educación, la vida familiar, las profesiones, el derecho, la cultura popular, el control de la natalidad, la literatura, las artes, la religión, el racismo y permitió el movimiento de liberación gay (Mack, 2004; Gordon, 2013).

A partir de lo anterior, se evidencia que los movimientos enfocados en el dualismo entre cultura-naturaleza, así como a la paz y el daño ambiental, en su relación con la opresión de la mujer y otras personas, son los principales pioneros de la tercera ola del feminismo que surge a finales de 1980 con el desarrollo de nuevas consideraciones, algunos autores han identificado tres tendencias que no son excluyentes: el feminismo generacional, el feminismo postcolonial y el ecofeminismo, los cuales se resisten a la destrucción de la "naturaleza no humana". En general esta nueva ola, prioriza el reconocimiento de la diversidad, de los diferentes puntos de vista, de nuevas preocupaciones entre las que se debe mencionar: la sexualización

6 La Nueva Izquierda se caracterizó particularmente por ser un movimiento en contra de la guerra y la oposición a la militarización de Estados Unidos en diferentes contextos del mundo (Butler, 1994). 
cultural de las niñas, el sexo y la tradicional categorización del género, las oportunidades de educación superior, los problemas ambientales y sus impactos; inquietudes que requieren del desarrollo de nuevos enfoques; cabe resaltar que el reconocimiento de la diversidad es un aspecto que no logra permear los movimientos de la segunda ola (Mack, 2004).

Tabla 3. Principales tendencias de la tercera ola del feminismo

\begin{tabular}{|c|c|c|}
\hline $\begin{array}{l}\text { Feminismo } \\
\text { generacional } \\
\text { Se comenzó a formar } \\
\text { en la década de } 1990\end{array}$ & Feminismo Poscolonial & $\begin{array}{l}\text { Ecofeminismo } \\
\text { Se masifica como } \\
\text { tendencia en los } \\
\text { años } 70\end{array}$ \\
\hline $\begin{array}{l}\text { Esta conformado por } \\
\text { jóvenes "diversas" que } \\
\text { crecen con el feminis- } \\
\text { mo y que perciben un } \\
\text { mundo diferente al de } \\
\text { sus antecesoras. }\end{array}$ & $\begin{array}{l}\text { Se plantea que las } \\
\text { preocupaciones de } \\
\text { esta tendencia fueron } \\
\text { gestadas por las jóvenes } \\
\text { feministas. }\end{array}$ & $\begin{array}{l}\text { Se fundamenta en } \\
\text { las relaciones entre el } \\
\text { militarismo, el sexismo, } \\
\text { el racismo y el daño } \\
\text { ambiental. }\end{array}$ \\
\hline $\begin{array}{l}\text { Articulan las similitudes } \\
\text { teóricas, las vivencias y las } \\
\text { diferencias; a partir de la } \\
\text { comprensión de los múlti- } \\
\text { ples aspectos que podrían } \\
\text { conformar la categoría } \\
\text { "mujeres", definiéndolo } \\
\text { como la "multiplicidad de } \\
\text { identidades". }\end{array}$ & $\begin{array}{l}\text { Se centra en la intersección } \\
\text { del sexismo y la formación } \\
\text { de la identidad multicultu- } \\
\text { ral, para incluir los efectos } \\
\text { negativos del legado } \\
\text { colonial occidental. }\end{array}$ & $\begin{array}{l}\text { Stephanie Leland y Leonie } \\
\text { Caldecott se reconocen } \\
\text { como las primeras expo- } \\
\text { nentes de está corriente } \\
\text { ecofeminista con su } \\
\text { libro Reclaim the Earth: } \\
\text { Women Speak Out for } \\
\text { Life on Earth publicado } \\
\text { en } 1983 \text {. }\end{array}$ \\
\hline $\begin{array}{l}\text { Logran vincular a las niñas } \\
\text { mediante dinámicas de } \\
\text { feminismo cultural que les } \\
\text { permite empoderarse con } \\
\text { ciertos valores sociales y } \\
\text { culturales, a través de la } \\
\text { música y las revistas; como } \\
\text { una forma de participar y } \\
\text { expresarse. }\end{array}$ & $\begin{array}{l}\text { Sus principales preocu- } \\
\text { paciones giran en torno } \\
\text { de las problemáticas } \\
\text { producto de la econo- } \\
\text { mía mundial capitalista, } \\
\text { que se manifiestan en } \\
\text { movimientos ambien- } \\
\text { tales por mujeres del } \\
\text { "tercer mundo". }\end{array}$ & $\begin{array}{l}\text { En la teoría ecofeminis- } \\
\text { ta confluye principios } \\
\text { de la ecología y del } \\
\text { feminismo como una } \\
\text { doctrina que propende } \\
\text { por la construcción de } \\
\text { una conciencia racio- } \\
\text { nalmente ambiental. }\end{array}$ \\
\hline
\end{tabular}




\begin{tabular}{|c|c|c|}
\hline $\begin{array}{l}\text { Feminismo } \\
\text { generacional } \\
\text { Se comenzó a formar } \\
\text { en la década de } 1990\end{array}$ & Feminismo Poscolonial & $\begin{array}{l}\text { Ecofeminismo } \\
\text { Se masifica como } \\
\text { tendencia en los } \\
\text { años } 70\end{array}$ \\
\hline $\begin{array}{l}\text { Se amplía la noción de } \\
\text { "interseccionalidad", } \\
\text { para Expósito (2012) la } \\
\text { interseccionalidad "hace } \\
\text { referencia a la situación en } \\
\text { la cual una clase concreta } \\
\text { de discriminación interac- } \\
\text { túa con dos o más grupos } \\
\text { de discriminación creando } \\
\text { una situación única" (p. } \\
\text { 205); lo cual es deno- } \\
\text { minado como la teoría } \\
\text { sociológica de la "repro- } \\
\text { ducción institucional de la } \\
\text { desigualdad". }\end{array}$ & $\begin{array}{l}\text { Platea debates en rela- } \\
\text { ción a la persistencia de } \\
\text { la neocolonialidad eco- } \\
\text { nómica y política; desde } \\
\text { la deconstrucción del } \\
\text { concepto de "desarrollo" } \\
\text { como sinónimo de pro- } \\
\text { greso, que contradice las } \\
\text { prácticas de las mujeres } \\
\text { campesinas e indígenas. }\end{array}$ & $\begin{array}{l}\text { Se caracteriza por } \\
\text { diferentes puntos de } \\
\text { vista que van desde } \\
\text { la resistencia local al } \\
\text { crecimiento económi- } \\
\text { co, sin perder de vista } \\
\text { la perspectiva global. } \\
\text { Plantea la interconexión } \\
\text { y la interdependencia } \\
\text { humana con lo natural. }\end{array}$ \\
\hline
\end{tabular}

Fuente: construcción propia a partir de (Mack, 2004)

\section{Canadá}

Los movimientos feministas en Canadá se evidencian y expresan principalmente en la provincia de Quebec, identificándose como "feminismo francófono o feminismo de la francofonía. Teniendo como marco una sociedad nacional en la cual el bilingüismo inglés/francés es oficial, al tiempo que la multiculturalidad tiene rango constitucional y se erige en torno al respeto, a la autonomía" (Castañeda, s.f.). Entre las principales características de estos movimientos feministas se encuentra la complejidad de los mismos, a partir de las diferencias de sus integrantes y sus constructos teóricos; por ende es difícil establecer una propuesta de pensamiento en este contexto; no obstante se resalta una corriente afín con la desarrollada en Estados Unidos, como es el caso del feminismo radical, mientras se encuentran corrientes alternas como el feminismo igualitario y el feminismo de la feminidad, con tendencias marxistas, existencialistas, estructuralistas, 
freudianas entre otras; pero conviene precisar que a pesar de la diferencia "las discusiones relativas a la situación de las mujeres, apareciera como un imperativo ubicarlas en el contexto del entramado de las relaciones que sostienen cotidianamente" (Castañeda, s.f.).

Las luchas femeninas en el contexto canadiense han logrado la reivindicación de sus derechos a partir de diversos instrumentos legales, entre los que se destaca: la carta canadiense de Derechos Humanos promulgada en 1977 y cuyo propósito principal es el de garantizar condiciones de igualdad en las oportunidades, evitando prácticas discriminatorias (Canadian Human Rights Act - Purpose of Act, 2012). Frente a los temas relacionados con la mujer se crea la organización denominada Status of Woman Canada, encargada de potenciar la participación de las mujeres en la vida económica, social y democrática; a través de proyectos relacionados con temáticas e iniciativas como: seguridad económica y prosperidad, liderazgo, fin de la violencia, ocupaciones no tradicionales, consejos, comunidades rurales, entre otros (Status of Women Canada, s.f.).

Aun cuando Canadá es percibido por el mundo como un país desarrollado, en particular por sus indicadores económicos; presenta situaciones de discriminación femenina laboral como en otros contextos, destacándose el tema de remuneración laboral por debajo de los hombres y de acuerdo a las conclusiones de Lara y Montoya (2007):

No es suficiente tener un alto capital humano para contar con un salario igual al del hombre que realiza actividades similares o comparables, pues se ha demostrado que por sí sola, esta teoría no explica dicha diferencia. Más bien es una combinación de factores individuales, familiares, económicos, políticos, y también de discriminación (p. 80).

\section{Asia}

En el continente asiático un referente es India, país donde los problemas de las mujeres han acompañado toda la historia del país, desde los inicios se 
ha pensado que la mujer tiene una categoría más baja, el nivel de inequidad ha tomado tales magnitudes que los problemas de violencia en dicho país son conocidos internacionalmente y son actuales, no se denota cambios en la problemática.

Amartya Sen, premio Nobel de economía de 1998, ha trabajado en temas generales de desarrollo y ha contribuido en algunos aspectos frente al problema de género. En el documento La misoginia como problema de salud pública (Sen, 2014), resume algunas de las problemáticas, que aunque son generalizadas en el mundo, son más marcadas en continentes como Asia y África: desigualdad en la mortalidad, asociada con las diferencias en la atención de salud; desigualdad en la natalidad, dada la preferencia por tener hijos hombres, en muchas sociedades se realizan abortos; desigualdad en el acceso a oportunidades básicas, especialmente a la educación, donde se ha llegado a extremos como en Afganistán que se prohíbe la educación a las niñas; desigualdad en oportunidades, en el acceso a educación superior se da un brecha entre hombres y mujeres inclusive en continentes como Europa; desigualdad profesional que básicamente se refiere a las diferencias entre género para acceder a cargos altos; desigualdad en las propiedades como medio de dominio hacia las mujeres; la desigualdad en el hogar en la distribución de labores domésticas.

Un referente importante es Afganistán, un cambio fundamental se da en 1990, gracias a las tendencias internacionales, "esto plantea conflictos entre sus nuevos derechos y los valores cuidadosamente promovidos por una jerarquía social patriarcal de larga data" (Agnihotri y Mazumdar, 1995, p. 1.872), adicionalmente considerando los casos de violencia tan frecuentes y $\tan$ impactantes que se dan en el país, Mazumdar (1997) añade que en la diferenciación de clases sociales para evitar mezclas se controla mediante las mujeres, donde se acentúa las diferencias de género. Dela misma forma afirma como condiciones necesarias para el desarrollo del país: a) igualdad de las mujeres como condición básica para el desarrollo social, económico y político, b) mejorar las condiciones de empleo de la mujer para que no sean dependientes, c) compartir la responsabilidad de la crianza de los 
hijos con los hombres, d) el oficio de ama de casa debe ser considerada actividad económica activa, e) el matrimonio y la maternidad no deben verse como discapacidades, y f) la responsabilidad de la eliminación de las desigualdades es de toda la sociedad (Mazumdar, 1994).

Una autora muy reconocida es Shiva (1991, 1992, 1992a), representante de una tendencia que se ha denominado feminismo ambiental y se refiere a las desigualdades de las comunidades locales que tienen incidencia sobre el daño ambiental, entre ellas las inequidades entre hombres y mujeres.

En el contexto de toda la problemática actual, una preocupación relevante es garantizar los derechos fundamentales de las mujeres, por lo que Batliwala (2011) propone alternativas para el desarrollo de las organizaciones que trabajan por esta causa. Como se evidencia la revisión en India presenta una gama muy amplia de temáticas en torno al género femenino.

Otro contexto que marca la diferencia, empezando por su densidad poblacional, es China, donde Xiaojiang (2006) afirma que hubo una gran revolución femenina en 1976, divide la nueva China (1959) en dos, respecto de los estudios de género, fecha donde la autora menciona que se presentó la liberalización de las mujeres y la configuración como grupo; previo a esta etapa, lo que sucedía con las mujeres en dicho país se resume de la siguiente forma: "los hombres son superiores y las mujeres son inferiores", por lo cual el único papel activo de la mujer era en la maternidad y el cuidado de los hijos. A partir de 1976 se presenta un cambio respecto a la exigencia de igualdad de derechos legales entre hombres y mujeres y la incursión de la mujer como individuo social.

Dentro de los procesos necesarios para el cambio social y económico, Suyin (1966) menciona como imprescindibles en el proceso de modernización chino, hacia el desarrollo igualitario, la educación para los dos géneros, la colectivización de la agricultura y el "cambio de actitud de hombres y mujeres hacia la valoración de su propio trabajo", ello con el fin de mejorar las condiciones de precios de bienes agrícolas y por ende de igualdad social. 
Zarrow (1988), Huiying (2003), Liu, Karl y Ko (2013) realizan un análisis del abordaje hecho por Yin Zhen acerca de diversas problemáticas, partiendo del manifiesto comunista de 1908, desde la economía, la política y en especial desde la visión capitalista, donde lo principal en temas de género es el argumento de que la esclavitud de las mujeres estaba arraigada en razones económicas, las principales causas se presentan por la desigualdad en la riqueza sostenida por "un sistema transnacional de acumulación capitalista" que incide inclusive en las decisiones de maternidad en las mujeres pobres. Zheng (2005) por su parte resalta la importancia de las instituciones en el apoyo de gestión de cambios hacia la igualdad de género.

Mon (2000) menciona que desde los antepasados chinos la cultura frente a las mujeres exige de ellas: sacrificio, castidad, piedad filial y la educación de los hijos, con ello los únicos cambios se han ido presentando por la entrada de la cultura occidental. Ying (2009) propone que en los desarrollos literarios en China, mejora la argumentación jurídica de los derechos de las mujeres.

Un aspecto importante es la esclavitud sexual que se dio en Japón durante la segunda guerra mundial, donde Stivens (2002) y Yamane (2010) narran cómo las condiciones del país en el momento hacen que se incremente la prostitución y toda clase de explotación sexual, pero al mismo tiempo surjan activistas como Yayori Matsui, en defensa de los derechos de las mujeres. Matsui (2001) plantea que "la esclavitud sexual militar de Japón antes y durante la segunda guerra mundial, fue una de las formas más terribles de la violencia sexual en tiempos de guerra contra las mujeres conocidas en este siglo" (p. 125), lo que fue juzgado por un tribunal de guerra propuesto y desarrollado por mujeres.

Un estudio que es referente es el de Kumamoto-Healey (2005), el cual pone en evidencia diferencias en la contratación en Japón entre 1947 y 2003 , llegando a la conclusión de que en la mayoría de entidades estudiadas el número de mujeres en los cargos directivos era mínimo por restricciones de acceso a esos cargos. 
Kasue (2006) presenta un análisis de cómo la política de la posguerra incentivaba que las mujeres se dedicaran al hogar y educaran los hijos, mientras los hombres fueran los responsables del sustento familiar, para ello proporcionaba más acceso a los niveles altos de educación a los hombres que a las mujeres.

En Corea del Sur una de la preocupaciones ha sido la violencia sexual, la autora Kyungja (2003), académica de la Universidad de Sydney, presenta un trabajo de cómo los movimientos feministas impactan sobre el abuso sexual, criticado en este entorno, por referirse a tendencias occidentales, concluyendo que dichos movimientos se van presentando por la necesidades y las condiciones de cada contexto. Por su parte Nam (2000) enuncia cómo los movimientos feministas de los años ochenta aportaron a la construcción democrática cambiando el impacto de los militares de la época.

Seungsook (2006) menciona que el cambio frente a la situación de las mujeres en los últimos cuarenta años ha sido muy importante y además afirma que: "este cambio no es meramente un resultado derivado de una transformación estructural general, sino también la consecuencia de una lucha colectiva intencionada" (p. 45), dado especialmente por los movimientos de las mujeres en los años ochenta.

En Indonesia un tema relevante a mencionar es la igualdad de género por los referentes religiosos, en el caso del Islam, Zakiyah $(2002 ; 2003)$ y Nurmila (2011) plantean lo siguiente: "la religión puede materializar la misión humanitaria en las sociedades pluralistas, a través de la protección de la fe, la vida, el intelecto, los descendientes y la riqueza", de acuerdo con la autora el Corán refuta el extremismo y el radicalismo caracterizados por la violencia, la intolerancia y la inhumanidad, dentro de estos planteamientos la mujer juega un papel fundamental, se afirma que dentro de las escrituras incluyen otros aspectos: "las mujeres pueden mantener el control sobre sus propiedades, se debe abolir la condición de mujer como propiedad y la libre decisión de divorcio" (p. 208), un cambio muy relevante frente a las creencias tradicionales. Raden Ajeng Kartini se considera un referente en temas de genero de los siglos XIX y XX, "su contribución particular fue aplicar las doctrinas de entonces el feminismo europeo contemporáneo a 
su propia sociedad...ella analizó una serie de males sociales y trabajaba en su solución" (Taylor, 1976, p. 644).

En Camboya hay una crónica muy preocupante realizada por Mam $(2007 ; 2010)$ sobre explotación sexual en mujeres y niños, muestra datos específicos acerca de estas terribles prácticas, como por ejemplo que decenas de niñas son vendidas a diario en ese país por sus familias para fines de explotación sexual, entre otras cosas, su experiencia particular es que ella fue vendida por su abuelo siendo una niña.

En Uzbekistán, de acuerdo con Arutyunova (2013), son muy significativas las necesidades de financiación de las organizaciones que trabajan por la igualdad de género.

En Birmania los autores Koistinen (2003), Herbert (1993), Yin Hlaing (2007) y Young Pelton describen a Aung San Suu Kyi como una de las principales defensoras de los derechos de las mujeres y de la lucha anticolonialismo británico, además describen cómo una de las mayores problemáticas de las minorías fue la imposición de la religión católica, dentro de un entorno de guerra y continua violación de los derechos humanos.

\section{Africa}

África, no es ninguna novedad, es el continente más golpeado, más expoliado, más postergado. Su población sigue pagando hoy día, entrado ya el siglo XXI, los estragos del colonialismo europeo que ayudaron a sentar las bases del capitalismo globalizado los pasados siglos. Pero no todo es resignación. Muchos levantan la voz; y, cosa muy interesante, muchas mujeres son abanderadas en la lucha por otro mundo distinto (Gotilla Umoya, 2014).

La autora Becky L. (2013), resalta la necesidad de que las mujeres en África se impacten por las tendencias mundiales en temas de género, ellas son las primeras en generar obstáculos frente a su papel en la familia y en la sociedad y como individuo aportante en la economía, cambios muy relevantes en el continente que presenta los problemas más graves que la 
pobreza. Otro aspecto que afecta bastante es el precio internacional del algodón, producto que se cosecha en varios países africanos (Traoré, 2010).

En Liberia se posesionó en el año 2005 como presidente Ellen Johnson Sirleaf, quien hizo una campaña por los derechos de las mujeres y para ejercer el derecho al voto por parte de estas.

La violencia contra las mujeres se utiliza para romper y humillar a los hombres, las familias, las comunidades, no importa de qué lado están. Las mujeres se han convertido en las peores víctimas de la guerra y los grandes grupos de interés de la paz (Rehn y Sirleaf, 2002).

En este trabajo se presentan las principales problemáticas de género que se dan en el contexto global, partiendo de lo referente a la violencia contra la mujer, los desplazamientos forzosos, los efectos de la guerra en su salud, el VIH como problema, se llega a describir inclusive casos donde se viola a mujeres dentro de los conflictos solo con el objetivo de infectarlas con el virus del Sida; asimismo proponen una solución a través de las negociaciones y un sistema de justicia adecuado llegando a reformas sociales muy relevantes (Sirleaf, 2009).

En Sudáfrica se han presentado toda clase de discriminaciones principalmente por razas y género, el apartheid tuvo un impacto profundo sobre los movimientos sociales y sobre el comportamiento histórico en temas raciales y políticos del país, el estudio de género no podría ir desligado al tema de raza porque son procesos complementarios. De acuerdo con Murphy (2002), los movimientos femeninos se dan por la entrada de las tendencias occidentales, sin embargo se incentivó por la necesidad de generar equidad dentro de la población.

En Egipto se encuentra un aporte muy relevante en temas de género dadas por Doria Shafik, quien impulsa la libertad y el reconocimiento de la mujer a nivel mundial (Nelson, 1996), en un país donde se hacen pruebas de virginidad y se obliga a llevar velo cubriendo el rostro (Jassat, 2012). 
En Etiopía existe un grave problema con las mujeres, de tipo físico, es la mutilación genital. De acuerdo con Gebre (2012), adicional a la escasa educación que se brinda en general y menos aún a las mujeres, acompañadas estas problemáticas de falencias económicas muy importantes, viven principalmente de agricultura, sin técnica alguna.

Ejike (2013), afirma que "la socialización del rol de género profundamente arraigada nunca ha hecho de la igualdad de género sea una realidad a pesar de las inmensas contribuciones de las mujeres al desarrollo de Nigeria en todos los ámbitos de la vida", la mencionada autora realizó un estudio de cómo influye el nivel de educación de las mujeres en la percepción de la igualdad de género en dicho país y concluyó que: "la tradicional socialización de género-rol en el sudeste de Nigeria ha seguido influyendo en cómo los hombres evalúan la igualdad de género a pesar de los esfuerzos de las Naciones Unidas y otros organismos para reducir la desigualdad”.

Así como se generan muchas dificultades para las mujeres en África, se presentan propuestas de mejoramiento, como las planteadas en la siguiente tabla:

Tabla 4.

Propuestas para mejorar la condición de la mujer y de la sociedad en general en África (Propuesta para Malí)

El refuerzo de la cohesión y la solidaridad entre hombres y mujeres en el marco de la relectura del Código de las personas y de la familia

La reactivación de la economía local

La defensa del derecho de la movilidad y del retorno de los migrantes

Defensa de la democracia

Garantizar el derecho de las mujeres a informarse sobre la descentralización y la globalización y todos los impactos económicos que traen estos fenómenos.

Fuente: elaboración propia a partir de (Traoré, 2010)

Se resalta las necesidades que en cuestiones económicas presentan las mujeres africanas, un aspecto relevante es mejorar condiciones y garantizar 
derechos económicos, como el derecho a la propiedad y garantizar el trabajo en igualdad de condiciones con los hombres.

Adicionalmente se identifican factores que facilitan y que frenan el desarrollo de las condiciones de la mujer, las cuales se presentan así:

Tabla 5

\begin{tabular}{l|l}
\hline Facilitadores & Impedimentos \\
\hline $\begin{array}{l}\text { Acceso a empleo formal y salarios } \\
\text { adecuados. }\end{array}$ & Violación de la igualdad de oportunidades \\
\hline $\begin{array}{l}\text { Acceso a trabajos independientes y a } \\
\text { propiedad de las empresas }\end{array}$ & El acceso limitado a la formación \\
\hline $\begin{array}{l}\text { Participación progresiva en sindicatos que } \\
\text { favorecen la unión de mujeres }\end{array}$ & Acoso sexual \\
\hline \multirow{2}{*}{$\begin{array}{l}\text { Políticas estatales económicas que abor- } \\
\text { den los temas de desarrollo, derechos de } \\
\text { los trabajadores y pobreza. }\end{array}$} & $\begin{array}{l}\text { Derechos de sucesión inadecuados para la } \\
\text { propiedad de la tierra. }\end{array}$ \\
\cline { 2 - 2 } & Lesigualdad salarial \\
\cline { 2 - 2 } $\begin{array}{l}\text { El papel de los movimientos de mujeres } \\
\text { en las organizaciones, con el fin de mejo- } \\
\text { rar las condiciones y el cumplimiento de } \\
\text { los derechos. }\end{array}$ & $\begin{array}{l}\text { Falta de apoyo para el trabajo de mujeres } \\
\text { con hijos, como guarderías. }\end{array}$ \\
\cline { 2 - 2 } & $\begin{array}{l}\text { Falta de redes de seguridad que apoyen a } \\
\text { las mujeres desempleadas }\end{array}$ \\
\hline
\end{tabular}

Fuente. Amman, 2004

En las anteriores líneas se vislumbran diferentes condiciones y problemáticas de las mujeres en Asia y África, situaciones de gran impacto a nivel social, ya que si una mujer se ve afectada en general la familia también, dentro de la gama de problemas se contemplan desde mutilación en los órganos genitales hasta desigualdad en las condiciones de trabajo, dificultades muy graves donde las alternativas deben surgir a partir de las mismas mujeres, proceso que se ha venido gestando y que en la actualidad cuenta con mujeres que están tomando el liderasgo para exigir el cumplimiento de sus derechos. 


\section{Latinoamérica}

Desde la década de los sesenta hasta los ochenta, algunos países latinoamericanos fueron dominados por dictaduras militares y apoyadas por los grupos económicos dominantes, con el fin de garantizar sus intereses e incidencia en las decisiones económicas; dentro de este modelo de gobierno dictatorial, se marca una fuerte opresión a la población, negando sus derechos civiles, políticos y sociales, persecución a los grupos opositores y violación sistemática de los derechos humanos, vale mencionar el caso de Chile con Augusto Pinochet (1974), Argentina con José Videla (1975), en Bolivia con Hugo Banzer (1971) y Paraguay con Alfredo Stroessner desde 1954 hasta 1989.

El caos social vivido durante estos años forjó movimientos sociales donde la mujer tuvo un papel protagónico liderando movimientos opositores, que promovían la eliminación de toda clase de discriminación contra ellas; y gracias a una presencia más marcada de la mujer en la vida universitaria, se inician los estudios de género, especialmente en temas sobre la mujer trabajadora del campo, la mujer indígena y la inserción de la mujer en la educación como en la política. Igualmente con gran eco en Latinoamérica se tomó como referente los acontecimientos que paralelamente se vivían en Europa y Estados Unidos, los cuales se centraban más en la emancipación de la mujer en la vida cultural, la familia, el lugar de trabajo, la libertad sexual y los derechos de reproducción.

Estos movimientos que se gestaron en su mayoría al interior de las universidades, lograron un apoyo de región, de tal manera que en 1981 se llevó a cabo el primer encuentro feminista de Latinoamérica y el Caribe, evento vigente en la actualidad y expresión de la equidad e inclusión de la mujer en la sociedad; además la Organización de Estados Americanos (OEA) y la Comisión Económica para América Latina y el Caribe (CEPAL) han sido líderes para América Latina en el apoyo de políticas de inclusión de la mujer en las esferas políticas, educativas y laborales. 


\section{México}

Gracias a los movimientos feministas promovidos durante los años setenta en los países latinoamericanos, en México el tema de equidad de género se incluyó en la agenda política, de tal manera que en el año de 1974 se logró la inclusión de la igualdad de la mujer en la Constitución Política de México, ya en el 2001 se creó el Instituto Nacional de Mujeres, con el objetivo principal de promover la protección de los derechos humanos; sin embargo, la falta de políticas públicas culturales que velen por el interés de la inclusión de género, la violencia y la pobreza en el país ha mantenido la exclusión de la mujer en la vida política, perpetuando la cultura patriarcal; no obstante y gracias a la participación de la mujer en la academia, en la década de los noventa se crearon en el país diversas instituciones y redes que trabajan por el bienestar de la mujer.

Tabla 6. Autoras Mexicanas destacadas

\begin{tabular}{l|l}
\hline Autora Mexicana & Aporte a los estudios de género \\
\hline Rosa María González & $\begin{array}{l}\text { Ha abordado en sus principales publicaciones la temática } \\
\text { de género desde la historia de las mujeres profesoras hasta } \\
\text { la formación científica y participación investigativa de las } \\
\text { docentes en el país de México. }\end{array}$ \\
\hline Eli Bartra & $\begin{array}{l}\text { En temas de educación superior, ha planteado las } \\
\text { principales contradicciones que enfrenta la mujer en las } \\
\text { Universidades. }\end{array}$ \\
\hline Blanca Elvira López & $\begin{array}{l}\text { En 1997 llegó a unas interesantes conclusiones en su } \\
\text { estudio denominado "Modelo de análisis de las trayectorias } \\
\text { de formación de investigadoras", afirma que las mujeres en } \\
\text { el espacio universitario cuentan con un rango inferior en } \\
\text { estatus académico, no se le facilita la participación en los } \\
\text { trabajos académicos: publicaciones y participaciones en } \\
\text { conferencias foros o debates y su participación en los órga- } \\
\text { nos e instancias administrativos es muy deficiente, a pesar } \\
\text { de ser la Universidad un espacio en el que formalmente no } \\
\text { existe discriminación, los hechos y relaciones sí evidencia } \\
\text { tales situaciones descritas, }\end{array}$ \\
\hline
\end{tabular}




\begin{tabular}{|c|c|}
\hline Autora Mexicana & Aporte a los estudios de género \\
\hline $\begin{array}{l}\text { Gabriela Delgado } \\
\text { Ballesteros }\end{array}$ & $\begin{array}{l}\text { Realizó un estudio desde la perspectiva de género, destaca } \\
\text { el tipo de contratación de las académicas universitarias en } \\
\text { 1995, titulado "Resignificando la condición de las mujeres } \\
\text { académicas de la Universidad Autónoma de México", } \\
\text { concluyendo que: } \\
\text {...La productividad académica se logra dependiendo del } \\
\text { ciclo de vida o después del maternaje. Estos aspectos se } \\
\text { evidenciaron claramente con el análisis de la currícula, } \\
\text { al encontrar espacios de baja productividad, tanto en las } \\
\text { horas frente a grupo como en la publicación de artículos, } \\
\text { manuales o libros. El dedicarse al maternaje impide un de- } \\
\text { sarrollo académico continuo, existen espacios temporales } \\
\text { de logros de actualización o grados académicos depen- } \\
\text { diendo de la época de la maternidad y el maternazgo... } \\
\text { (Gómez, 2011. p10.) }\end{array}$ \\
\hline Norma Blázquez Graff, & $\begin{array}{l}\text { "Ha publicado diversos artículos sobre las mujeres en la } \\
\text { ciencia, en estos trabajos la autora destaca los avances que } \\
\text { han tenido las mujeres en la ciencia, el lugar que ocupan } \\
\text { en el Sistema Nacional de Investigadores en cada una de } \\
\text { las áreas de conocimiento. Así como también señala la dis- } \\
\text { criminación que han sido objeto las mujeres científicas en } \\
\text { las evaluaciones para escalar niveles en el Sistema Nacional } \\
\text { de Investigadores y para obtener recursos para desarrollar } \\
\text { proyectos de investigación relacionados con los temas } \\
\text { de las mujeres, los cuales son financiados por el Consejo } \\
\text { Nacional de Ciencia y Tecnología". (Gómez, 2011. p10.) }\end{array}$ \\
\hline Rosario Castellanos & $\begin{array}{l}\text { Narradora y poeta mexicana, la más importante del siglo } \\
\text { XX en su país, Trabajó en el Instituto Indigenista Nacional } \\
\text { en Chiapas y en Ciudad de México, preocupándose de } \\
\text { las condiciones de vida de los indígenas y de las mujeres } \\
\text { en su país, Su poesía, en la que destacan los volúmenes } \\
\text { Trayectoria del polvo (1948) y Lívida luz (1960), revela } \\
\text { las preocupaciones derivadas de la condición femenina. } \\
\text { Biografías y Vidas. }\end{array}$ \\
\hline
\end{tabular}




\begin{tabular}{l|l}
\hline Autora Mexicana & Aporte a los estudios de género \\
\hline Graciela Hierro & $\begin{array}{l}\text { Fue fundadora y directora del Programa Universitario de } \\
\text { Estudios de Género (PUEG) de la UNAM. A lo largo de su } \\
\text { vida académica participó en múltiples eventos nacionales } \\
\text { e internacionales en los cuales presentó diversas investiga- } \\
\text { ciones sobre filosofía feminista. Dedicó la mayor parte de } \\
\text { su vida académica a apoyar el desarrollo de investigaciones } \\
\text { feministas. En su labor como filósofa creó las condicio- } \\
\text { nes necesarias para impulsar el desarrollo de la filosofía } \\
\text { feminista dentro de los espacios universitarios. Su trabajo } \\
\text { trascendió los ámbitos académicos y cobró importancia en } \\
\text { las esferas política y cultural mexicanas. }\end{array}$ \\
\hline
\end{tabular}

Fuente: elaboración propia, a partir de Gómez, 2011 y Dorantes, 2006

\section{Colombia}

Gracias a la influencia de las expresiones de género de Estados Unidos y Europa en todos los países latinoamericanos, Colombia a través de un grupo importante de mujeres participó en el proceso de dignificación de los derechos políticos, sociales y civiles de las mujeres colombianas, a través de diferentes grupos señalados por Arango y Puyana (2007):

En la década del setenta, en Colombia surgió la segunda ola del feminismo, dividido entre las mujeres que se revelaban contra todo tipo de institucionalidad -incluso la partidista-, y las que se encontraban vinculadas a los partidos políticos como la izquierda socialista y la Unión de Mujeres Demócratas del Partido Comunista. Medrano (como se citó en Arango y Puyana, 2007). Estos grupos incidieron en el desarrollo de los estudios de género en la Universidad Nacional de Colombia, ya que la mayoría de las fundadoras del Grupo Mujer y Sociedad provenían de grupos socialistas y troskistas, del Partido Comunista o del Nuevo Liberalismo. Sin embargo, en el primer encuentro feminista que organizaron en 1981 en Sopó (Cundinamarca), se planteaba la necesidad de construir un nuevo sentido de luchas feministas, ajenas a todo tipo de institucionalidad (p. 122). 
En 1981, el Estado colombiano ratificó y convirtió en ley la convención aprobada por la Organización de Naciones Unidas (ONU) en 1979, sobre la eliminación de todas las formas de discriminación contra la mujer. Si bien las primeras políticas públicas hacia la mujer tendían a resaltar su papel como madres, durante el gobierno de Belisario Betancourt (19821986) comenzó a cambiar esta concepción. En los ministerios de trabajo y agricultura se propusieron programas con perspectiva de género, y desde el Departamento Nacional de Planeación (DNP) se promulgó en 1984 la política para la mujer campesina, al reconocer su papel en la producción agropecuaria y la necesidad de cambiar la tradicional división sexual de roles (Arango y Puyana, 2007, p.124).

Luego en los noventa y con el apoyo de grupos feministas, se promulgó la constitución de 1991, la cual señala:

La mujer y el hombre tienen iguales derechos y oportunidades. La mujer no podrá ser sometida a ninguna clase de discriminación. Durante el embarazo y después del parto gozará de especial asistencia y protección del Estado, y recibirá de éste subsidio alimentario si entonces estuviere desempleada o desamparada. El Estado apoyará de manera especial a la mujer cabeza de familia (Artículo 43).

Igualmente se promovió el acceso a la mujer al sistema educativo y al mercado laboral; paralelamente a este impulso por parte del gobierno y sus políticas públicas de inclusión de la mujer en los procesos laborales y educativos especialmente, en las universidades se crearon estudios de género. Es importante mencionar que un detonante para reclamar los derechos de las mujeres es el conflicto armado, ya que se ha utilizado la violencia sexual como estrategia de guerra. 
Tabla 7. Autoras colombianas destacadas

\begin{tabular}{|c|c|}
\hline Autoras Colombianas & Aporte a los estudios de género \\
\hline Magdalena León & $\begin{array}{l}\text { Profesora titular de la Facultad de Ciencias Humanas } \\
\text { de la Universidad Nacional de Colombia en Bogotá, } \\
\text { pionera en Colombia en estudios de género en Colombia } \\
\text { y Latinoamérica, fue directora de las Investigaciones que } \\
\text { dieron origen a los libros. }\end{array}$ \\
\hline Luz Gabriela Arango & $\begin{array}{l}\text { Integrante de la Escuela de Estudios de Género de la } \\
\text { Universidad Nacional de Colombia, parte fundamental } \\
\text { en la elaboración del Acuerdo } 035 \text { de equidad de género } \\
\text { y de igualdad de oportunidades para mujeres y hombres } \\
\text { en la Universidad Nacional de Colombia, actualmente } \\
\text { lidera dos proyectos de equidad de género en la educación } \\
\text { superior: el proyecto MISEAL "Medidas para la inclusión } \\
\text { social y equidad en Instituciones de educación superior } \\
\text { en américa latina" y el proyecto FEGES, "Fortalecimiento } \\
\text { de capacidades relacionadas con la equidad de género en } \\
\text { la educación superior en Colombia" }\end{array}$ \\
\hline Florence Thomas & $\begin{array}{l}\text { En la década de 1980, con otras profesoras, logró } \\
\text { constituir el Grupo Mujer y Sociedad en la Universidad } \\
\text { Nacional de Colombia, del cual se mantiene como } \\
\text { coordinadora, constituyéndose como punto cardinal para } \\
\text { la investigación y el debate académico sobre género. Ese } \\
\text { proceso, ya en los 90, sentaría las bases de la Escuela de } \\
\text { Estudios de Género, Autora de los siguientes libros: El } \\
\text { macho y la hembra reconstruidos (1985), Los estragos } \\
\text { del amor (1995) y Conversación con un hombre ausente } \\
\text { (1997). Palabras en el tiempo, Género: Femenino y La } \\
\text { mujer tiene la palabra. Gallo (2011). }\end{array}$ \\
\hline Yolanda Puyana & $\begin{array}{l}\text { Docente de la Escuela estudios de género. De la } \\
\text { Universalidad Nacional de Colombia, Investigadora en el } \\
\text { proyecto denominado Cambios y conflictos en las familias } \\
\text { a raíz de la migración internacional. Proyecto financiado } \\
\text { por Colciencias y coordinado por la universidad Nacional } \\
\text { con las universidades del Valle, Cartagena, Caldas y } \\
\text { Antioquia. }\end{array}$ \\
\hline
\end{tabular}

Fuente: elaboración propia a partir de Arango y Puyana, 2007 y Gallo, 2001 


\section{Chile}

Hablar de estudios de género en Chile es reconocer su origen en organismos no institucionales, propiciados especialmente por un grupo de mujeres exiliadas durante la dictadura, que regresaron al país con estudios de posgrados en la materia y necesitaban reivindicar sus derechos políticos, sociales y culturales en una nueva democracia, logrando trascender su labor académica hacia las universidades formalmente desde la década de los $90 \mathrm{y}$ el trabajo de algunas mujeres parte de las ONG donde se documentaba las vivencias de las mujeres en ámbitos públicos y privados, logrando iniciar a nivel nacional un proceso de equidad de género en sus políticas públicas:

En el año 2002 se incluye el enfoque de género como uno de los aspectos estratégicos del Programa de Mejoramiento de la Gestión (PMG), entregando una señal explícita sobre el rol del Estado en la construcción de relaciones más equitativas en políticas, programas y reformas legislativas que consideren las diferencias de género en la distribución de beneficios y tareas sociales (Arcos, Figueroa, Miranda y Ramos, 2007, p. 3).

Las mujeres escritoras a través de sus documentos reafirmaron su oposición frente al autoritarismo vivido en Chile durante la dictadura, reflexionando sobre el papel de la mujer en la vida social, laboral y política, y planteando nuevos objetos de estudio en temas de género, a continuación se mencionan algunas autoras y sus aportes a este nuevo campo de investigación.

Tabla 8. Autoras destacadas chilenas

\begin{tabular}{l|l}
\hline Autora Chilena & Aporte a los estudios de género \\
\hline Olea, Raquel & Ha ejercido su labor como investigadora desde diversas \\
& academias y, especialmente, desde la corporación feminista \\
& La Morada. Es autora y editora de varios trabajos de literatura \\
& feminista, entre los cuales destacan la compilación Volver a la \\
& memoria, en coedición con Olga Grau (2001), El género en apu- \\
& ros: discursos públicos: Cuarta Conferencia Mundial de la Mujer, \\
& compilado junto a Olga Grau y Francisca Pérez (2000), Escrituras \\
& de la diferencia sexual (2000), Lengua víbora: producciones de lo \\
& femenino en la escritura de mujeres chilenas (1998) y Ampliación \\
& de la palabra: la mujer en la literatura (1995). \\
\hline
\end{tabular}




\begin{tabular}{l|l}
\hline Sonia Montecino & $\begin{array}{l}\text { En la década de los noventa formó, junto a la Profesora Loreto } \\
\text { Rebolledo y otras académicas, el Centro de Estudios de Género } \\
\text { (CIEG) que antes fue un Programa y que desde hace } 20 \text { años se } \\
\text { ha dedicado a promover la teoría de género en la docencia de pre } \\
\text { y posgrado, la extensión, investigación y publicaciones, así como } \\
\text { en el mundo social. }\end{array}$ \\
\hline
\end{tabular}

Fuente: elaboración propia, a partir de Memorias Chilenas (s.f.).

\section{Argentina}

El actual papel de la mujer en la vida política y social en Argentina tiene sus inicios en el fenómeno del peronismo, caracterizado principalmente por una política populista, centrada en un discurso de justicia social y soberanía nacional que luego de muchos años en el poder, fue reemplazado por una violenta dictadura militar desde el año 1976 hasta el año 1983, gobierno que se caracterizó por la desaparición forzosa de miles de personas, violación de derechos humanos, robo de recién nacidos, entre otras muchas características criminales, situaciones que llevaron a la sociedad a reaccionar contra estos tipos de violaciones de derechos humanos, especialmente vale la pena mencionar la conformación de grupos cívicos liderados por mujeres y familiares de las víctimas, como las madres de la plaza de mayo organizadas con el fin de solicitar al gobierno la entrega de los desaparecidos, este colectivo de mujeres se consolidó dando inició a otros movimientos feministas como las abuelas de la plaza de mayo, que en la actualidad luchan por la ubicación de los nietos robados durante la dictadura, una vez terminado el régimen y aprovechando los procesos de recuperación democrática fomentados por el gobierno, se dio inicio a posibilidades de estudios de género en las universidades gracias al liderazgo de mujeres investigadoras académicas, que promovieron políticas públicas dirigidas a reivindicar los derechos y el papel de la mujer en el país y a trabajar por la erradicación de la violencia doméstica, especialmente.

Este país se convirtió en el primero en América Latina en aprobar la Ley de cupos, donde se establece un número mínimo del $30 \%$ de participación 
femenina en las listas electorales, situación que ha llevado a aprobar leyes progresistas a favor de las mujeres en materia sexual y reproductiva:

Como el matrimonio igualitario que permite el casamiento de personas del mismo sexo (2010) y la ley de identidad de género (2011) que posibilita tener la identidad civil de acuerdo con la identidad sexual/género subjetiva y dentro de la agenda actual el gobierno trabaja en temas como la legalización del aborto, la accesibilidad gratuita y segura a los servicios de salud para abortar y la prerrogativa de decidir sobre el propio cuerpo (Barrancos, 2012).

Refiriéndose al tema específico de la situación de la mujer a nivel mundial es conocido que hay dos continentes que tienen contextos muy difíciles para este género, esta realidad parte de problemas religiosos, políticos, económicos y culturales muy fuertes, esto lleva a la preocupación de examinarlos, son problemáticas y autores referentes los cuales se han movido por la realidad tan cruda que afecta a las mujeres.

\section{Conclusiones}

En todo el mundo se evidencian serias problemáticas en temas discriminatorios contra las mujeres. En Europa los movimientos feministas nacen como respuesta a un sistema patriarcal que prevaleció durante varias décadas y que afectó considerablemente el contexto social. En Norteamérica por su parte ha sido muy notable la discriminación social, laboral y de rechazo en la esfera pública. En Latinoamérica hubo una marcada discriminación civil y política por parte de algunas dictaduras y regímenes extremistas, muchas veces por legados de países europeos. Asia y África son los continentes con mayores problemáticas en temas de exclusión drástica contra las mujeres; en contraste con otros países, en India por ejemplo, son muchas las prácticas de discriminación selectiva que aún prevalecen, en el acceso a educación, en el ámbito laboral para alcanzar cargos directivos y en general la creencia por tradición que los hombres siempre serán superiores a las mujeres. 
En otros países como Japón y Corea del sur, la prostitución y la esclavitud sexual son muy marcadas; en Indonesia, el arraigo por temas religiosos crea estandartes sociales de intolerancia; y en general se ha adoptado posturas para catalogar a las mujeres como minorías en todo el sentido de la palabra. Siguiendo esta postura, África ha soportado un legado que por tradición es excluyente del resto del mundo, la discriminación racial se convierte en un agravante que justifica en mayor medida la degradación de las mujeres, y hechos tan drásticos como las prácticas de mutilación genital manifiestan las evidentes dificultades que han tenido en asuntos de igualdad de género. La respuesta a estos hechos se manifiesta desde varios puntos de vista, por ejemplo con la conformación de instituciones defensoras de los derechos de la mujer, desde la vía normativa mediante emisión de leyes que hacen más incluyentes a las mujeres y una marcada expresión de rechazo por parte de las diferentes autoras, creando redes y movimientos revolucionarios que en algunas ocasiones se encaminan hacia un feminismo radical con un impacto plenamente social.

\section{Referencias}

Agnihotri, I., \& Mazumdar, V. (1995). Changing terms of political discourse: Women's movement in India, 1970s-1990s . Economic and political weekly, 1.869-1.878.

Amman, J. (2004). Regional strategies for empowering women. Baghdad: Wooddrow Wilson International Center for Scholar.

Arango, L. G., y Puyana, Y. (2007). Género, mujeres y saberes en América Latina:entre el movimiento social, la academia y el Estado. Bogotá: Universidad Nacional de Colombia. Facultad de Ciencias Humanas, Escuela de Estudios de Género.

Arutyunova, A. (2013). Watering the leaves starving the roots: The status of financing for women's rights organizing and gender equality. Recuperado de http://awid. org/Library/Watering-the-Leaves-Starving-the-Roots

Arcos, G. E., Figueroa A, V., Miranda J., C., y Ramos, C. (2007). Estado del arte y fundamentos para la construcción de indicadores de género en educación. Estudios pedagógicos, 33(2), 121-130.

Ávila, M. (2012). Teoría e historia del movimiento feminista. Castilla, España. 
Barrancos, D. (2012). Los caminos del feminismo en Argentina, 32. Recuperado de http://www.vocesenelfenix.com/

Batliwala, S. (2011). Strengthening monitoring and evaluation for women's rights:

Thirteen insights for women's. Recuperado de http://www.awid.org/Library/ Strengthening-Monitoring-and-Evaluation-for-Women-s-Rights-ThirteenInsights-for-Women-s-Organizations

Becky, L. J. (2013). Unbound by theory and naming: Survival feminism and the women of the South African Victoria mxenge housing and development association. Berkeley journal of gender, Law \& Justice, 19-77.

Butler, J. (1994). Sexual traffic. 62-99. (G. Rubin, interviewer) Journal of feminist cultural studies.

. (2012). Canadian human rights act - Purpose of act. Recuperado de http:// laws-lois.justice.gc.ca/eng/acts/h-6/page-1.html\#h-2

Carnero, S. (2005). La condición femenina desde el pensamiento de Simone de Beauvoir. A parte Rei: Revista de filosofía, 40.

Castañeda, M. (s.f.). La antropología social y el feminismo en Canadá: aproximaciones a las tendencias francófonas. Omnia. Recuperado de http://www.posgrado. unam.mx/publicaciones/ant_omnia/41/16.pdf

Centro de Estudios de Género, Mujer y Sociedad. (s.f). Quiénes somos. Recuperado de http://genero.univalle.edu.co/centro.htm

Ciriza, A. (2012). Simone de Beauvoir. De la fenomenología del cuerpo a la utopía de la libertad. Revista Nomadías, 16, 11-21.

Collazo, L. (2005). De la mujer a una mujer. Otras miradas, 5(2), 52-65. . (1991). Constitución Política de Colombia. Recuperado de www.constitucioncolombia.com/

Dayan, J. (1982). Simone de Beauvoir: por ella mismas (2a edición). (J. Delgado, trad.). Buenos Aires, Argentina: Losada S. A.

Dorantes, G. (2006). La condición humana en la obra de Graciela Hierro. Recuperado de http://www.ensayistas.org/critica/generales/C-H/mexico/hierro.htm

Duby, G., y Perrot, M. (1993). Historia de las mujeres en occidente (Tomo \% ed.). (M. Galmarin, trad.). Taurus Ediciones.

Ejike, A. O. (2013). Attitude towards gender equality in South-eastern Nigerian culture: Impact of gender and level of education. Gender \& Behaviour, 5.579-5.585. 
. (s.f.). Escuela de estudios de género. Recuperado de http://www.humanas. unal.edu.co/genero/

Estevez, M. (2003). Vigencia y relevancia de la obra de Hélène Cixous en la actualidad. Philologia hispalensis, (17)2, 147-156.

Expósito, C. (2012). ¿Qué es eso de la interseccionalidad? Aproximación al tratamiento de la diversidad desde la perspectiva de género en España. Investigaciones feministas, 3, 203-222.

Fiscer, G. (2013). El feminismo español en la segunda mitad del siglo XX. Revista de Clases de historia, 348, 1-15.

Gallo, C. (2001, 13 de febrero). La "matria" de Florence Thomas. UN periódico. Recuperado de http://www.unperiodico.unal.edu.co

Gebre, B. (2012). Global ChanGe leaders case study. Antigonish: Coady International Institute.

Gómez, E. R. (2011). Género, educación y universidad. Un acercamiento a la historiografía de México. Diálogos revista electrónica, 5(1-2).

Gordon, L. (2013). Socialist feminism: The legacy of the "second wave". New labor forum, 22(3), 20-28.

Gotilla, F. (2014, 26 de junio). ENcontrARTE. Recuperado de http://www.lafogata. org/mujer/cra_preg.htm

Grau, O. (2014). La escritura de Simone de Beauvoir como proyecto global. Revista chilena de literatura, 86, 121-132.

Heim, D., y Bodelón, E. (2009). Derechos de género e igualdad: cambios en las estructuras jurídicas androcéntricas (Vol. I). Grupo Antígona y “Dones i Drets”. Barcelona, España: Universidad Autónoma de Barcelona.

Herbert, P. (1993). Freedom for fear and others writings by Aung San Suu Kyi. Bulletin of school of oriental and african studies, 187-188.

Huiying, L. (2003). Feminism: An organic or an extremist position? On tien yee as represented by He Zhen. Positions, 11, 779-800.

Jassat, F. (2012). Revolutionary women. New Internationalist, 18.

Kasue, M. (2006). Las mujeres japonesas del siglo XX y más allá. A. Sáiz López. Mujeres asiáticas: cambio social y modernidad, 15-36. Barcelona: CIBOD Ediciones.

Koistinen, A. (2003). Peace profile: Aung San Suu Kyi. Peace review, 15(3), 349-355. 
Kumamoto-Healey, J. (2005). Las mujeres en el mercado laboral japónes de 1947 a 2003. Revista Internacional del Trabajo, 485-508.

Kyungja, J. (2003). Practicing Feminism in South Korea: The issue the sexual violence and the women's movement. Hecate, 261-284.

Lara, T., y Montoya, E. (2007). La desigualdad de género en el mercado laboral canadiense - ¿Discriminación vigente o ejemplo a seguir? El caso de Carleton. Revista.

Liu, L. H., Karl, R. E., \& Ko, D. (2013). The Birth of Chinese Feminism: Columbia University Press, 328-330.

Lonzi, C. (1970). Manifiesto de rivolta femminile. Roma, Italia.

Maclean, N. (1999). The hidden history of affirmative action - Working women's struggles in the 1970s and the gender of class. 25(1), 42-78.

Mack, C. (2004). Third-Wave feminism and the need to reweave the nature/culture duality. NWSA Journal, 16(3), 154-179.

Mam, S. (2007). Silencio y obediencia: la explotación sexual en el sureste asiático. Política Exterior, 21, 99-101.

Mam, S. (2010). Interview with Cambodian activist. Recuperado de http:// www.amazon.com/Interview-cambodian-activist-Somaly-slavery/dp/ B003K4KCGA

Matsui, Y. (2001). Women's international war crimes tribunal on Japan's military sexual slavery: Memory, identity and society. East Asia, 119-142.

Mazumdar, V. (1994). Women's studies and the women's movement in India: An overview. Women's studies quarterly, 42-54.

Mazumdar, V. (1997). India (Fall/Winter 1994). Women's studies quarterly, 341-344.

Memorias Chilenas. (s.f). Recuperado de http://www.memoriachilena.cl

Mendes, K. (2011). Framing feminism: News coverage of the women's movement in british and american newspapers, 1968-1982. Social movement studies, 10(1), 81-98.

Mon, M. (2000). The economic position of women in Burma. Asian studies review 24, 243-255.

Murphy, R. (2002). Unstable categories: Comparing the politics of gender in the early 1990s in Canada and South Africa. 300-340.

Nam, J. L. (2000). Gender politics in the Korean transition to democracy. Korean studies, 94-112. 
Nelson, C. (1996). Doria Shafik, egyptian feminism: A women apart. Recuperado de http://www.jstor.org/discover/10.2307/23061460?uid=3737808\&uid=212 9\&uid $=2 \&$ uid $=70$ \&uid $=4 \&$ sid $=21104213331537$

Nurmila, N. (2011). The influence of global muslim feminism on indonesian muslim feminist discourse. Al-Jamah 49, 33-64.

Ortega, C. (2002). Miradas de género de Woolfa Haraway. UOC Estudis Literaris.

Ramírez, C. (2003). Fuentes y recursos para los estudios de mujeres y de género en Francia. Philologeia hispalensis, 167-191.

Ramos, M. (2003). Cómo escribir un artículo de revisión. Revista de posgrado de la VIa cátedra de medicina, (126), 1-3.

Rehn, E., \& Sirleaf, E. J. (2002). Women, war and peace: The independent experts' assessment on the impact of armed conflict on women and women's role in peace-building. New York: United Nations Development Fund for Women.

Sen, A. (2014, 7 de marzo). Desigualdad de género. La misoginia como problema de salud pública. Recuperado de http://www.letraslibres.com/revista/convivio/ desigualdad-de-genero-la-misoginia-como-problema-de-salud-publica

Seungsook, M. (2006). Cambio social y situación de las mujeres en Corea del Sur: familia, trabajo y política. A. Sáiz López, Mujeres asiáticas cambio social y modernidad, 37-74. Barcelona: CIDOB Ediciones.

Shiva, V. (1991). Biotechnology development and conservation of biodiversity. Economic and political weekly, 2.740-2.746.

Shiva, V. (1992). Environmental extremism. Economic and political weekly, 2.564.

Shiva, V. (1992a). Women's indigenous knowledge and biodiversity conservation. India international centre quarterly, 205-214.

Sirleaf, E. J. (2009). I am proud of what we have achieved. New African, 38-43.

Status of Women Canada. (s.f.). Recuperado el 13 de junio de 2014 de http://www. swc-cfc.gc.ca/index-eng.html

Stivens, M. (2002). Women in the new Asia: From pain to power by Yayori Matsui. Journal of southeast asian studies, 3, 345-346.

Suyin, H. (1966). Reflections on social change. Bulletin of the atomic scientists, 22(6), 80-83.

Taylor, J. S. (1976). Raden Ajeng Kartini. Signs 3, 639-661.

Traoré, A. (2010). Mujeres de África, justicia y gobernanza. Tiempo de paz, 96, 32-35. 
Travis, T. (2008). The women in print movement: History and implications. Book History (Pennsylvania State University Press), (11), 275-300.

Woolf, V. (1929). Una habitación propia. Barcelona: Seix Barral.

Xiaojiang, L. (2006). Ganancias y pérdidas de las mujeres en la construcción y la transición de la República Popular China: Panorámica de la liberación y del crecimiento de las mujeres en China desde 1949. A. Sáiz López. Mujeres Asiáticas cambio social y modernidad, 77-107. Barcelona: CIDOB ediciones.

Yamane, K. (2010). Yayori Matsui and the women's active museum on war and peace. Social alternatives 29, 25-28.

Yin, K. (08 de 2007). Aung San Suu Kyi of Myanmar: A review of the Lady's biographies. Contemporary Southeast Asia, 359-376.

Ying, H. (2009). How Can a Daughter Glorify the Family Name? Nan Nü, 11, 235-269.

Young, R. (s.f.). The Black Zone. Recuperado de http://www.vqronline.org/essay/ black-zone

Zakiyah, L. (2002). He is your garment and you are his...: Religious, precepts, interpretations, and power relations in marital sexuality among javanese muslim women. Sojourn 17, 191-220.

Zakiyah, L. (08 de 2003). Women, islam and human security. Recuperado de http://www.lfip.org/laws718/docs/lily-pdf/Women,\%20Islam\%20and\%20 Human\%20Security.pdf

Zarrow, P. (1988). He Zhen and anarcho-feminism in China. The journal of asian studies 47, 796-813.

Zheng, W. (2005). State Feminism? Gender and socialism state formation in maoist China. Feminist studies 31, 519-551. 